\section{$\underset{\substack{\text { hommes } \\ \text { \& migrations }}}{ }$}

\section{Hommes \& migrations}

Revue française de référence sur les dynamiques

migratoires

$1297 \mid 2012$

Migrations en création

\title{
Fabien Nury (scénario), Brüno (dessin), Atar Gull. Ou le destin d'un esclave modèle
}

Paris, Dargaud, 2011, 88 pages, 16,95 euros

\section{Mustapha Harzoune}

\section{(2) OpenEdition}

1 Journals

Édition électronique

URL : http://journals.openedition.org/hommesmigrations/1611

DOI : 10.4000/hommesmigrations. 1611

ISSN : 2262-3353

Éditeur

Musée national de l'histoire de l'immigration

Édition imprimée

Date de publication : 1 mai 2012

Pagination : 168-169

ISSN : 1142-852X

\section{Référence électronique}

Mustapha Harzoune, «Fabien Nury (scénario), Brüno (dessin), Atar Gull. Ou le destin d'un esclave modèle », Hommes \& migrations [En ligne], 1297 | 2012, mis en ligne le 29 mai 2013, consulté le 22 septembre 2020. URL : http://journals.openedition.org/hommesmigrations/1611 ; DOI : https:// doi.org/10.4000/hommesmigrations. 1611

Ce document a été généré automatiquement le 22 septembre 2020.

Tous droits réservés 


\section{Fabien Nury (scénario), Brüno (dessin), Atar Gull. Ou le destin d'un esclave modèle}

Paris, Dargaud, 2011, 88 pages, 16,95 euros

\section{Mustapha Harzoune}

\section{RÉFÉRENCE}

Fabien Nury, Brüno, Atar Gull. Ou le destin d'un esclave modèle, Paris, Dargaud, 2011, 88 pages, 16,95 euros

1 Le captivant scénario de cette BD est une adaptation fidèle du roman d'Eugène Sue paru en 1831. Atar Gull raconte le destin du fils du roi de la tribu des Petits Namaquas, réduit à la condition d'esclave dans une plantation de la Jamaïque et qui, prisonnier d'une terrible soif de vengeance, sombrera dans une folie meurtrière tout en suscitant l'admiration pour son dévouement et sa servilité apparente. Car cet Atar Gull, sorte de gigantesque armoire à glace, est un malin, une personnalité double, complexe. Ici, l'esclave n'est pas plus sympathique que le maître. Ce qui donne à ce récit et aux dessins de Brüno un aspect effrayant qui tient le lecteur en haleine jusqu'à la dernière planche.

2 Le livre s'ouvre sur la traite négrière. Encore enfant, Atar Gull a fait le serment de ne jamais pleurer. Même pas quand les siens, capturés par la tribu rivale des Grands Namaquas, sont revendus aux négriers blancs. Ce commerce du "bois d'ébène" est ici particulièrement bien décrit, de manière clinique, froide, et les dessins vont à l'essentiel.

3 Nous sommes en 1830, le capitaine Benoit s'adonne aux juteux commerce triangulaire sur son brick Catherine, prénom de sa dulcinée restée à Nantes, où elle calme sa peine et ses ardeurs avec le médecin de famille. Sur terre, Paul Van Harp exerce son terrible et lucratif office d'intermédiaire entre les tribus africaines et les marchands. Il y a même 
dans les parages un certain Brulart, pirate cruel qui guette les navires lourds de leur “ chargement" qui s'éloignent de la côte africaine. Pour pas un sou, juste quelques coups de canon et de fusils, il s'empare de la "marchandise" et du bateau. La traversée est effroyable : sur une bonne centaine de "nègres", il n'en reste que 17 à l'arrivée. Comme disent ces messieurs: le "déchet" est énorme! Le solide Atar Gull est acheté par un certain Tom Will. Le planteur est un humaniste qui préfère la bienveillance à la force pour gérer son petit monde d'esclaves. Mais l'économie dicte ses règles : un vieillard incapable de travailler est "une perte considérable" et doit être expédié ad patres. Question de comptabilité! Il suffit de l'accuser de vol et hop! Ni une ni deux on le pend à un arbre.

4 Cela arrive aussi sur la plantation du "bon" Tom Will. Manque de chance, le vieillard n'est autre que le père de "l'esclave modèle" Atar Gull. L'homme, fidèle à son lointain serment, ne pleure pas. Il décide de se venger. Sa vengeance sera inexorable, injuste, cruelle. Emportant tout avec elle, jusqu'à sa raison. L'intensité dramatique est constante. Et bien sûr cette longue chaîne qui part de Benoît et file jusqu'à Will en passant par Van Harp est constituée de personnes respectables, d'époux fidèles et de pères attentifs au devenir de leur fille. Les "civilisés" ce sont eux. Quant à Atar Gull, il ne vaut pas plus cher que ces esclavagistes de bon aloi.

5 Tout cela est sombre et à désespérer de l'espèce! Cette BD est une réussite sur le plan historique comme sur le plan narratif. Tout y est : le commerce d'esclaves, la traversée, une bataille navale, le marché aux esclaves, l'organisation du travail dans la plantation, la société des planteurs et les festivités coloniales et même Nantes sous la neige. Et tout est admirablement rendu par les dessins de Brüno. 